\title{
Catalytic performance of microporous materials for the production of renewable fuels
}

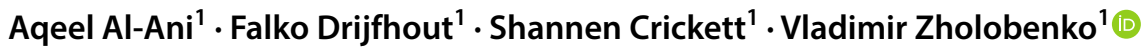

Published online: 26 April 2018

(c) The Author(s) 2018

\begin{abstract}
ETS-10, zeolite A and sepiolite based nano-structured materials were prepared and modified with potassium containing compounds using ion-exchange or impregnation and evaluated as basic catalysts for transesterification of vegetable oils using microwave heating. The structural features of these catalysts were characterised in detail by the variable temperature in situ $\mathrm{X}$-ray diffraction, $\mathrm{N}_{2}$ adsorption-desorption, scanning electron microscopy with energy dispersive $\mathrm{X}$-ray analysis and in situ FTIR spectroscopy using adsorption-desorption of acetylene as a basic probe in order to evaluate their structure-catalytic performance relationship in the methanolysis of triglycerides. A wide range of parameters were utilised in order to optimise the reaction conditions. Although a high yield of fatty acid methyl esters with almost 100\% selectivity can be achieved in transesterification reactions in the presence of K-containing sepiolite, this system shows significant deactivation due to its structural degradation and loss of the active component during the reaction and regeneration cycles. In contrast, zeolite KA and ETS-10, which are thermally stable crystalline materials, demonstrated no decrease in their activity for up to four reaction runs, and therefore can be used as effective solid basic catalysts in this reaction. Here we explore for the first time how the thermal and structural stability of the supported clay can affect its activity, an essential issue which has not been sufficiently studied in the recent research related to the biofuel production over solid catalysts.
\end{abstract}

Keywords Sepiolite $\cdot$ Zeolite A · ETS-10 · Impregnation · Ion-exchange · FAMEs · Transesterification · Microwave catalysis

\section{Introduction}

There are three major sectors that are utilising most of the energy worldwide: industry, power generation and transportation. The total energy consumed in 2010 was $5.53 \times 10^{20} \mathrm{~J}$, which is predicted to rise further to $8.65 \times 10^{20} \mathrm{~J}$ by 2040 [1]. This would constitute a 56\% rise between 2010 and 2040, and a considerable part of this is to be generated from renewable sources. Security of the energy supply, global warming

Electronic supplementary material The online version of this article (https://doi.org/10.1007/s10934-018-0610-7) contains supplementary material, which is available to authorized users.

Aqeel Al-Ani

a.a.t.al-ani@keele.ac.uk

$\triangle$ Vladimir Zholobenko

v.l.zholobenko@keele.ac.uk

1 School of Chemical and Physical Sciences, Keele University, Keele, Staffordshire ST5 5BG, UK and price fluctuation of non-renewable fossil fuel are the main factors for the development of renewable fuels [2]. Numerous studies on biofuels, such as bioethanol, biodiesel and biogas, have been conducted in order to address these issues. Biofuel can be considered as an alternative to conventional petroleum-based fuel because of the similarity between their properties. In addition, using biofuel has the potential to decrease the effects of global warming because the crops reuse $\mathrm{CO}_{2}$ which is essential for the photosynthesis process of the plant life cycle [3].

According to the American Society for Testing and Materials (ASTM), biodiesel can be defined as "a fuel comprised of mono-alkyl esters of long-chain fatty acids derived from vegetable oils or animals fats, designated B100" [4]. Although biodiesel has attractive properties such as high cetane values, lower sulphur content and good lubricity and can be used in compression ignition engines, one of the problems of biodiesel production is highlighted by the 'food vs. fuel' debate. The criticism is focused on the continuous use of edible oils for biodiesel production 
in the USA, Brazil, European and Asian countries, which impacts the global food security, leaving less fertile land available for food production and leading to further deforestation. Furthermore, there are problems associated with the fuel properties, as the higher molecular mass triglycerides (TGs), which are highly viscous compounds with a low volatility, may form deposits in biodiesel engines [5]. All these issues call for a new generation feedstock with high oil content and lower cost of cultivation as the world biofuel production continues to grow [6].

Non-edible oils with significant lipid amounts have been reported in the literature as potential sources for biofuel production $[3,5-8]$. These could reduce the cost of biodiesel production and enhance the global supply of automotive and power generation fuel. Therefore, more research effort is devoted to the development of this and other types of renewable fuel, which are also referred to as the second and third generation biofuels.

Transesterification is a reversible reaction between TGs in oils and fats with three small alcohol molecules, e.g. methanol or ethanol, in the presence of an acid or base using a homogenous or heterogeneous catalytic reaction to produce three molecules of monoester and glycerol. Broadly speaking, homogenous catalysts cannot be reused and the reaction products require purification resulting in the additional costs of the production of biodiesel [9], which can be made more economically viable by recovering the used catalyst and eliminating further separation processes. Hence, solid catalysts may be a viable alternative potentially offering lower production cost, high stability and the ease of separation. Nanoporous materials have received much attention in catalytic applications for a number of reasons, including the effects related to their pore size and shape, chemical functionality and increased surface area $[8,10,11]$. Many studies have illustrated the use of alkaline, alkaline earth and transition metal oxides supported on nanoporous materials with the pore size up to $50 \mathrm{~nm}$, such as silicas, clays and zeolites prepared by impregnation, ion exchange and precipitation, as highly active catalysts. This is associated with the high surface area, stability of active sites and their enhanced reactivity $[12,13]$.

A number of studies have focused on the applications of porous materials, e.g. layered double hydroxides, sepiolite and zeolites, as solid catalysts in transesterification of oils [14-19]. The reported yield of fatty acid methyl esters (FAMEs) obtained after several hours at $60-90{ }^{\circ} \mathrm{C}$ would typically exceed $90 \%$. Regrettably, many papers do not describe the structural characterisation of the clay based catalysts before and after the reaction studies, which in turn are often limited to a very small number, if any, of the successive runs on regenerated catalysts. Hence, factors that could affect the catalyst performance, including deactivation, loss of the active component, structural integrity and thermal stability [20], are not being sufficiently addressed.

In this work, potassium containing sepiolite and zeolite A (LTA structure type, $\mathrm{Si} / \mathrm{Al}=1$ ), as well as Engelhard titanium silicate (ETS-10) material have been prepared and modified via wet impregnation and ion-exchange and then used for the production of biofuel from both renewable oils using microwave heating. Sepiolite, a common clay, is a hydrated magnesium silicate containing continuous 2-D tetrahedral and octahedral sheets with the chemical formula $\left[\mathrm{Mg}_{8} \mathrm{Si}_{12} \mathrm{O}_{30}(\mathrm{OH})_{4} \cdot 4\left(\mathrm{H}_{2} \mathrm{O}\right) \cdot \mathrm{nH}_{2} \mathrm{O}\right]$, characterised by microfibrous morphology with micropore channels of $0.36 \times 1.06 \mathrm{~nm}$ and high specific surface area [15]. Zeolite $\mathrm{A}$ is one of the most commonly used materials in ion exchange and separation, which demonstrates basic properties in its potassium form. ETS-10 is a microporos inorganic material which contains a three dimensional 12 -membered ring pore system. It has corner sharing octahedral sites for titanium(IV) and tetrahedral sites for silicon and also shows a basic character [21]. The aim of the present study is to compare the catalytic performance of the three types of basic solid catalysts in the production of biofuel from renewable oils. A particular emphasis is on the detailed structural characterisation of the catalysts both before and after the reaction in order to evaluate the structure-performance relationship in the methanolysis of oils and to examine the mechanism of their deactivation. In this work, we demonstrate how the differences in the catalytic performance of these materials, particularly their reusability, can be linked to their structural stability.

\section{Experimental}

The Spanish sepiolite and phenolphthalein (ACS reagent) were obtained from Sigma-Aldrich. NaA zeolite was provided by Crosfield. Potassium hydroxide $(86 \%)$, sodium hydroxide, methanol, ethanol and n-heptane and n-hexane (analytical grade, $>99.99 \%$ ) were purchased from Fisher Scientific. Refined rapeseed oil and grapeseed oil were purchased from a local market; castor oil was obtained from Fisher Scientific and triolein (technical grade, 65\%) from Sigma-Aldrich. Deuterated chloroform (99.8 atom \% D) was from Cambridge Isotope Laboratories. Methyl heptadecanoate (analytical GC standard, >99.99\%) was supplied by Sigma-Aldrich. ETS-10 samples were synthesised as described in Electronic Supplementary Information section (ESI).

$\mathrm{KOH}$ impregnated sepiolite samples were prepared via the wet impregnation method with the water absorption by the clay matching the available void space of the pores in sepiolite particles [16]. In a typical preparation, $8 \mathrm{~g}$ of sepiolite was placed into a $250 \mathrm{~mL}$ round bottom flask. Then 
$2 \mathrm{~g}$ of $\mathrm{KOH}$ and $40 \mathrm{~mL}$ of deionised water were added and stirred for $2 \mathrm{~h}$ at ambient temperature to produce a homogeneous slurry. Next, the slurry was dried overnight at $60{ }^{\circ} \mathrm{C}$ to remove excess water. $\mathrm{K}$-Sepiolite was then calcined in a furnace at different temperatures up to $450{ }^{\circ} \mathrm{C}$ for $4 \mathrm{~h}\left(1{ }^{\circ} \mathrm{C} /\right.$ min temperature ramp). The ion-exchanged $\mathrm{K}$-sepiolite was obtained following the procedure described in reference [12].

KA zeolite was prepared by treating $\mathrm{NaA}$ with $0.1-0.5 \mathrm{~mol} / \mathrm{L}$ solution of $\mathrm{KNO}_{3}$ at $80{ }^{\circ} \mathrm{C}$ for $1 \mathrm{~h}$. Next, the exchanged sample was washed with deionised water and dried overnight. Before use, the zeolite was activated in a muffle furnace from room temperature to the desired temperatures (up to $450{ }^{\circ} \mathrm{C}$ ) at a rate of $1{ }^{\circ} \mathrm{C} / \mathrm{min}$ for $2 \mathrm{~h}$ in a flow of air.

All the catalysts were characterised before and after the reaction studies using powder X-ray diffraction (XRD), scanning electronic microscope (SEM) with energy dispersive X-ray analysis (EDX) and in situ FTIR spectroscopy.

Powder XRD patterns were recorded on a Bruker D8 Advance diffractometer with $\mathrm{Cu} \mathrm{K} \alpha$ radiation at $40 \mathrm{kV}$ and $40 \mathrm{~mA}$ at ambient temperature over the 2-theta angle range of $5-60^{\circ}$. The crystalline phases were matched by comparing the XRD patterns of the catalysts with those reported in the literature. In addition, sepiolite based catalysts were characterised at $50-540{ }^{\circ} \mathrm{C}$ using variable temperature XRD (VT-XRD) in a high-temperature in situ cell (Anton Paar) attached to a Bruker D8 diffractometer.

A TM3000 (Hitachi) SEM with EDX was utilised to obtain the elemental composition of the catalysts. Highresolution SEM images of zeolites were obtained using a PHILIPS XL30 instrument.

The apparent surface areas of the zeolitic catalysts were calculated using the BET model for the $\mathrm{P} / \mathrm{P}_{\mathrm{o}}$ relative nitrogen pressure $<0.04$; their micropore volume and the pore size distribution were computed using the nonlinear density functional theory (NLDFT) model applied to the adsorption branch of the isotherms obtained from the nitrogen adsorption experiments carried out on a Quantachrom Autosorb instrument. The values obtained were scaled to the mass of the activated samples, which was determined by thermogravimetric analysis (TGA).

TGA analysis of sepiolite has been carried out using a Rheometric Scientific STA 1500 instrument. The change in the sample weight and the heat flow were measured as a function of temperature (ramped from 20 to $900{ }^{\circ} \mathrm{C}$ at $10{ }^{\circ} \mathrm{C} / \mathrm{min}$ ).

FTIR spectra were collected using a Thermo iS10 spectrometer in the range $6000-1000 \mathrm{~cm}^{-1}$ with the resolution of $4 \mathrm{~cm}^{-1}$ and 64 scans in transmission mode. Prior to recording the spectra, the self-supported sample disks $(\sim 10 \mathrm{mg} /$ $\left.\mathrm{cm}^{2}\right)$ were heated in a vacuum cell at $30-450{ }^{\circ} \mathrm{C}\left(\operatorname{ramp} 1{ }^{\circ} \mathrm{C} /\right.$ $\min )$. After a period of $5 \mathrm{~h}$ at the selected temperature, the sample was cooled to $30{ }^{\circ} \mathrm{C}$ in vacuum and its IR spectrum was collected. The spectra of adsorbed acetylene were obtained at different pressures at $30{ }^{\circ} \mathrm{C}$.

Both edible and non-edible oils have been used as model feedstock. The analysis of oils, details of the reaction studies carried out in a Biotage microwave system and identification of the reaction products are described in ESI. Following the transesterification reaction, the catalysts were separated, washed with methanol and dried overnight at $60^{\circ} \mathrm{C}$. The dry catalysts were characterised by XRD and SEM-EDX. The recycled catalysts were calcined under the same conditions as prior to the initial reaction and utilised again in this reaction. The same reaction conditions were used in up to four consecutive runs for the recycled catalysts.

\section{Results and discussion}

In order to investigate the activity of solid catalysts in the transesterification of oils, a series of experiments was conducted using a batch type reactor under conventional and microwave heating. Figure 1 shows the conversion of rapeseed oil into methyl esters at different reaction times. Our results demonstrate significantly shortened reaction times as compared to the literatures $[18,23]$. The significant acceleration of the transesterification reaction can be explained by the higher temperatures that are achieved in our system using microwave irradiation, which is a fast and efficient way of heating the reaction mixture due to the high polarity of methanol [13]. The distribution of the reaction products has been monitored by ${ }^{1} \mathrm{H}$ NMR, GC-MS and FTIR (Tables S1-S3; Figures S1-S3, ESI). Although there is a considerable difference in microwave absorption by methanol and the oil, no unusual selectivity patterns have been observed for this reaction in comparison with the systems utilising conventional heating. Similar results were obtained in the reaction studies using other oils.

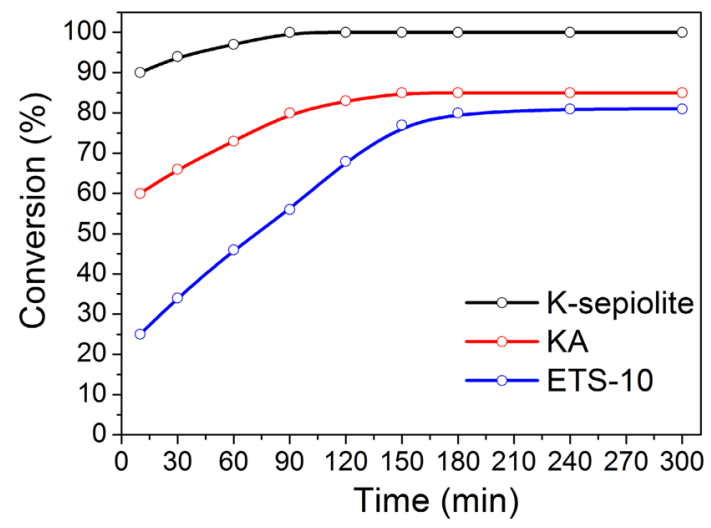

Fig. 1 Effect of the reaction times on the conversion of rapeseed oil 
The highest yield (75\% conversion, $~ 100 \%$ selectivity) has been obtained in the conventional heating mode after $3 \mathrm{~h}$. Microwave heating can greatly enhance the reaction rate $[22,23]$, and the highest conversion $(97 \%)$ has been observed within a shorter period using the highest temperature achievable with the Biotage microwave equipment $\left(160{ }^{\circ} \mathrm{C}\right.$ for the methanol based reaction systems). To determine the effect of $\mathrm{K}$-sepiolite, the catalyst amount in the reaction mixture was varied between 1 and $7 \%$ by weight. The conversion data presented in Fig. 2 demonstrate a significant increase in TGs conversion with increasing catalyst amount.

Table 1 presents a comparison of the catalytic performance for K-sepiolite, KA zeolite and ETS-10 in transesterification reaction. Although K-sepiolite exhibits the highest conversion in the first run, by the third run it is the least active catalyst. In contrast, both KA and ETS-10 yield almost the same results over the three consecutive runs. These data demonstrate a significant deactivation of potassium containing clay, which could be linked it its structural integrity and loss of the active sites. Although the initial
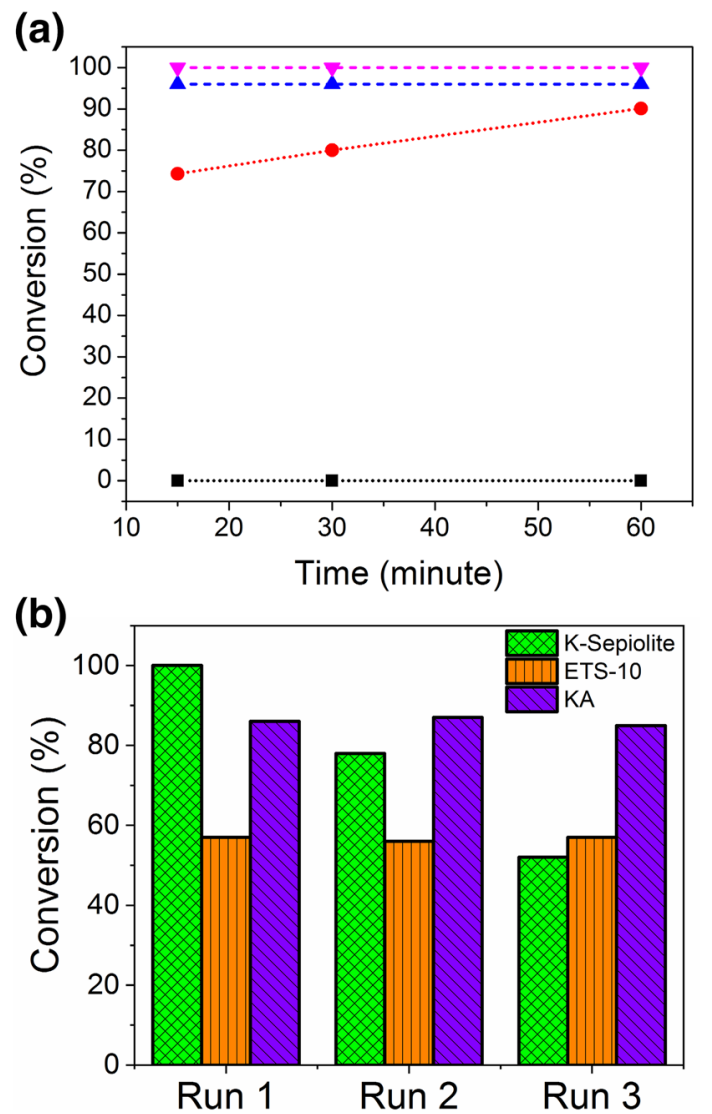

Fig. 2 a Conversion of rapeseed oils to FAMEs using K-sepiolite at $160{ }^{\circ} \mathrm{C}$ : black dotted line for $0 \mathrm{wt} \%$, red dotted line for $1 \mathrm{wt} \%$, blue dashed line for $3 \mathrm{wt} \%$ and pink dashed line for $7 \mathrm{wt} \%$. b Reaction profiles for K-sepiolite, zeolite KA and ETS-10. (Color figure online)
Table 1 Conversion of oils to FAMEs using KA, ETS-10 and K-sepiolite

\begin{tabular}{lclll}
\hline Oil & Entry $^{\mathrm{a}}$ & Catalysts & $\begin{array}{l}\text { Conversion } \\
(\%)^{\mathrm{b}, \mathrm{c}}\end{array}$ & Selectivity (\%) \\
\hline Rapeseed & 1 & KA & 86 & $>99$ \\
& 2 & ETS-10 & 57 & $>99$ \\
& 3 & K-Sepiolite & 97 & $>99$ \\
Grapeseed & 4 & KA & 74 & $>99$ \\
& 5 & ETS-10 & 45 & $>99$ \\
& 6 & K-Sepiolite & 97 & $>99$ \\
Castor & 7 & KA & - & - \\
& 8 & ETS-10 & 50 & $>99$ \\
& 9 & K-Sepiolite & 91 & $>99$ \\
Triolein & 10 & KA & - & - \\
& 11 & ETS-10 & 20 & $>99$ \\
& 12 & K-Sepiolite & 95 & $>99$ \\
\hline
\end{tabular}

${ }^{\mathrm{a}} 1: 6$ of methanol to oil molar ratio, reaction time $60 \mathrm{~min}, 160{ }^{\circ} \mathrm{C}$, $5-10 \mathrm{wt} \%$ amount of catalyst

${ }^{\mathrm{b}}$ Conversion for the first reaction run

${ }^{\mathrm{c}}$ Reactions were performed in triplicate and the experimental error was estimated as $\pm 3 \%$

activity of ETS-10 and KA is not very high, they clearly demonstrate a good deal of potential as basic catalyst for biofuel production, which is a challenging application involving bulky TGs molecules. Considering that the basic properties of zeolitic materials can be tuned by changing their chemical composition and the accessibility of active sites can be improved by designing hierarchical structures, it should be possible to further enhance their performance.

The structural properties of these materials have been monitored by XRD, FTIR and $\mathrm{N}_{2}$ adsorption. Figure 3 and S4 present the in situ VT-XRD patterns of the sepiolite and $\mathrm{K}$-sepiolite recorded at different calcination temperatures.

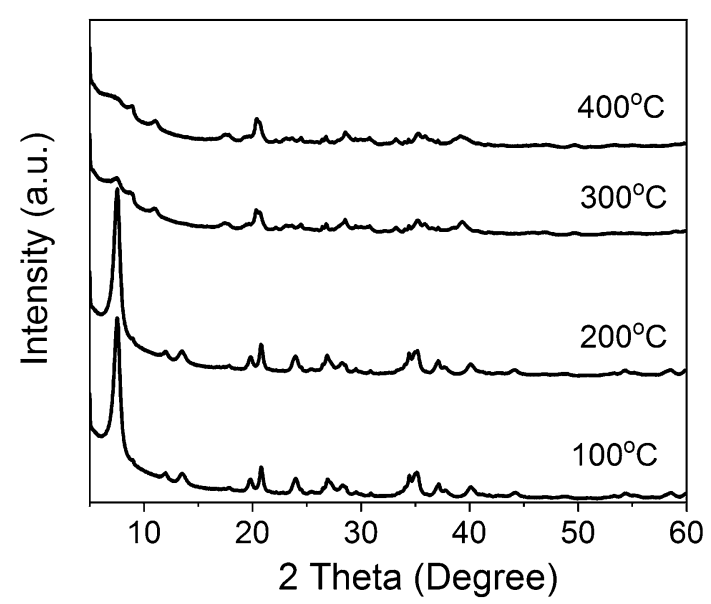

Fig. 3 In situ VT XRD patterns of the parent sepiolite collected every $100{ }^{\circ} \mathrm{C}$ (heating up). Patterns are offset for clarity 
There are clear changes in the patterns of both materials recorded above $200{ }^{\circ} \mathrm{C}$. For sepiolite in particular, the intensity of the peak at $7.48^{\circ}(1.18 \mathrm{~nm} \mathrm{~d}$-spacing), which corresponds to the interlayer distance in the clay structure, decreases significantly, becoming negligible above $300{ }^{\circ} \mathrm{C}$. Similar intensity changes are observed for the same peak (1.19 nm d-spacing) in the patterns of the K-sepiolite sample. It can be suggested that the layered structure of the catalyst has collapsed during the high temperature calcination.

Our results are in accord with the data reported in the literature [24-33] indicating that sepiolite structure shows significant changes upon heating above $250{ }^{\circ} \mathrm{C}$, which is accompanied by the loss of water from the material. These results and most literature data, however, disagreed with those presented in reference [18], which suggested that heating sepiolite to $500{ }^{\circ} \mathrm{C}$ does not cause any change in the catalyst structure. Our nitrogen adsorption and TGA-DSC data support the VT-XRD finding. Indeed, the surface area of sepiolite decreases with increasing activation temperature from 325 to $130 \mathrm{~m}^{2} / \mathrm{g}$ between (Fig. 4); the apparent BET surface area of K-sepiolite is below $100 \mathrm{~m}^{2} / \mathrm{g}$. In agreement
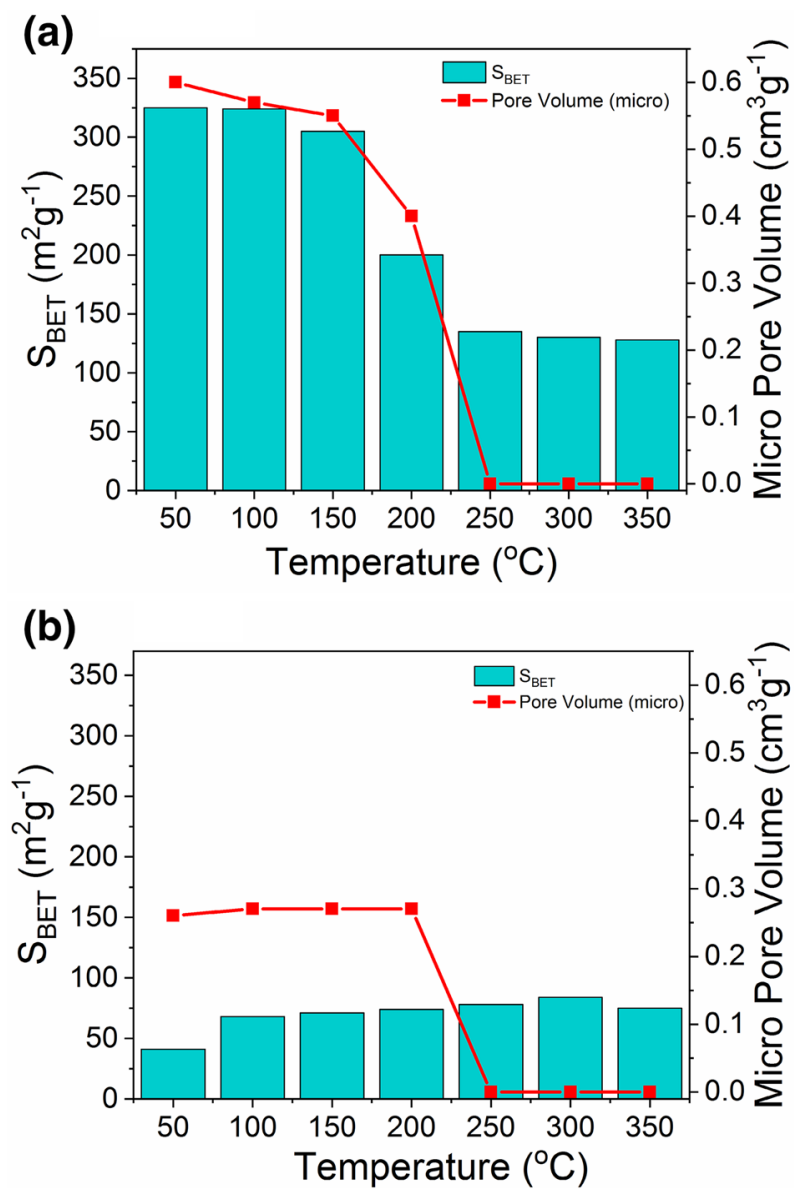

Fig. 4 Surface area and micropore volume for sepiolite (a) and K-sepiolite (b) with previous reports [28-31], the micropores present in the original sepiolite $(\sim 0.8 \mathrm{~nm}$ in diameter) in the spaces between the silicate layers are no longer detected for the samples activated at temperatures above $200{ }^{\circ} \mathrm{C}$ for sepiolite and $100{ }^{\circ} \mathrm{C}$ for $\mathrm{K}$-sepiolite.

Although the thermal treatment process is essential to decompose the metal precursor with the formation of an oxide on the support, there is a significant change in the catalyst properties caused by heating it up to $400{ }^{\circ} \mathrm{C}$, which is associated with the loss of water and the collapse of the layered structure. In agreement with previous studies [20, 26, 32], TGA-DSC data confirm the stepwise removal of water from sepiolite, which accounts for $~ 9 \%$ of the weight loss at $100{ }^{\circ} \mathrm{C}$ and $\sim 4 \%$ at $250-300{ }^{\circ} \mathrm{C}$ (both steps are endothermic processes as expected) with the total weight loss of $\sim 18 \%$ by $900{ }^{\circ} \mathrm{C}$ (Figure S5, ESI). The data obtained for $\mathrm{K}$-sepiolite are largely very similar, but show a more gradual removal of water from this material as compared to the parent sepiolite sample.

Chemical analysis and SEM images for sepiolite, zeolite A and ETS-10 are presented in Table S4 and Figure S6 (ESI). XRD data for these materials are presented in Figure S7 (ESI) and their nitrogen adsorption isotherms in Figure S8 (ESI). These patterns are in agreement with those reported in the literature [21,33, 34]. Importantly, for zeolite A and ETS-10 they also do not change after several reaction--regeneration cycles for both catalysts. As noted already, both activity and selectivity of these materials in transesterification of various oils remain the same for three consecutive reaction runs, which is in contrast to the performance of K-sepiolite.

The $\mathrm{OH}$ region of the FTIR spectra of sepiolite are presented in Fig. 5. The evolution of the spectral bands of different types of $\mathrm{OH}$ groups has been followed in situ during the sample dehydration between 30 and $450{ }^{\circ} \mathrm{C}$.

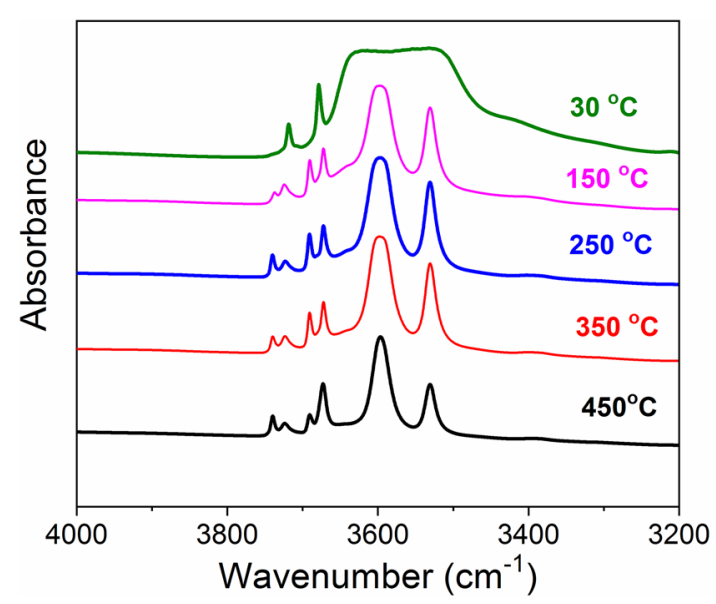

Fig. 5 The OH-region of FTIR spectra of sepiolite activated at different temperatures. Spectra are offset for clarity 
The initial spectra are dominated by the broad feature at $\sim 3650-3300 \mathrm{~cm}^{-1}$ owing to weakly bound water molecules, which are removed upon mild dehydration at $150{ }^{\circ} \mathrm{C}$. The spectra of the dehydrated samples exhibit six peaks in the region of stretching $\mathrm{O}-\mathrm{H}$ vibrations. In agreement with the literature [20, 35-39], the peaks at 3740 and $3724 \mathrm{~cm}^{-1}$ are assigned to $\mathrm{Si}-\mathrm{OH}$ groups of the tetrahedral silicate layer and those at 3691 and $3673 \mathrm{~cm}^{-1}$ to $\mathrm{Mg}(3)-\mathrm{OH}$ groups in the octahedral sheets of the sepiolite structure. The bands at 3597 and $3531 \mathrm{~cm}^{-1}$ have been attributed to water molecules coordinated to $\mathrm{Mg}$ cations. The spectra of $\mathrm{K}$-sepiolite dehydrated at elevated temperatures display rather broad overlapping bands between 3750 and $3600 \mathrm{~cm}^{-1}$. This is in agreement with our VT-XRD and nitrogen adsorption data indicating some considerable structural degradation upon $\mathrm{KOH}$ impregnation and calcination of this material.

The basic sites of the prepared catalysts have been characterised by the adsorption of acetylene as a probe molecule monitored by FTIR. For sepiolite, a high intensity peak of the $\mathrm{C}-\mathrm{H}$ stretching vibration is observed at $3208 \mathrm{~cm}^{-1}$ representing a $79 \mathrm{~cm}^{-1}$ shift as compared to the gas phase value for acetylene of $3287 \mathrm{~cm}^{-1}$. This is due to acetylene molecules interacting with basic oxygen atoms with the formation of a hydrogen bond [40]. Slightly more basic oxygen sites are detected in $\mathrm{K}$-sepiolite, the $\mathrm{C}-\mathrm{H}$ stretching vibration at $3202 \mathrm{~cm}^{-1}$, however, the intensity of the corresponding infrared band is very low.

The mechanism of deactivation of sepiolite based systems was examined as the structural stability, high surface area and strong bondings with the active phase preventing the loss of the active sites during the reaction and regeneration cycle are essential characteristics of the supported catalysts utilised in catalytic processes, including the production of biofuel [41]. Although we have obtained high yield and selectivity of FAMEs in the presence of K-sepiolite, this material lacks long-term stability in the methanolysis reaction. In contrast to our results and the data available in the literature, Degirmenbasi et al. [18] concluded that a higher catalytic activity of sepiolite impregnated with $\mathrm{K}_{2} \mathrm{CO}_{3}$ in the transesterification of canola oil is achieved following its calcination to $500{ }^{\circ} \mathrm{C}$, apparently resulting in a catalyst more resistant toward the leaching of the active phase. However, our structural characterisation, chemical analysis and catalytic data for the sepiolite-based catalysts that have been calcined or regenerated at temperatures between 250 and $600{ }^{\circ} \mathrm{C}$ provide no evidence of enhanced catalytic performance or improved structural stability following the high temperature treatment. In addition, characterisation of the regenerated catalysts shows that the potassium containing species are leaching out during the transesterification reaction or the regeneration step, which is accompanied with a significant drop in the yield of FAMEs in the subsequent catalytic runs, from 100 to 55\%, as demonstrated in Fig. 6. A

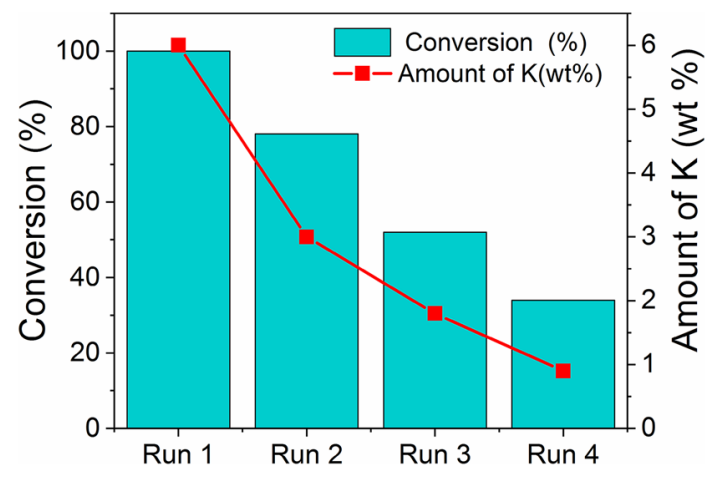

Fig. 6 Reaction profile and amount of potassium in the fresh and used K-sepiolite

similar drop in activity was observed for the ion-exchanged K-sepiolite.

Furthermore, in a blank reaction run with $0.0035 \mathrm{~g}$ of $\mathrm{KOH}$-approximately the amount of potassium hydroxide lost by sepiolite-based material in the first reaction cyclethe TGs conversion of $\sim 70 \%$ has been observed, confirming that dissolved $\mathrm{KOH}$ is active in the transesterification reaction. Overall, our reaction studies and structural analysis point to a potentially significant contribution of the homogeneously catalysed transformation of TGs. Clearly, such effects should be taken into account considering a significant number of studies utilising clay based solid catalysts either impregnated or ion-exchanged with potassium-containing compounds [12, 18, 41-45]; these can undergo irreversible structural changes during the catalyst activation and regeneration or in the course of the reaction. This is in contrast with the results obtained on thermally stable crystalline materials, zeolite KA and ETS-10, whose activity is associated with the basic properties of the framework oxygen and the stability of the active sites in the zeolitic structures [46-48]. Furthermore, a recent study indicates that in the transesterification of TGs over a series of modified zeolites, the basic strength of the active sites rather than their accessibility determines the catalytic activity of mesoporous faujasites [49].

\section{Conclusion}

The application of heterogeneous catalysts in the production of biodiesel offers potential advantages including lower cost, high stability and the ease of separation. In this work, ETS10 , zeolite KA and K-sepiolite were prepared and modified using ion-exchange or impregnation. These nano-structured materials were assessed as basic catalysts for transesterification of vegetable oils utilising conventional heating and microwave irradiation. The structural characterisation of these catalysts was conducted using variable temperature 
in situ XRD, $\mathrm{N}_{2}$ adsorption-desorption, scanning electron microscopy with energy dispersive X-ray analysis and in situ FTIR spectroscopy to evaluate their structure-catalytic performance relationship. A wide range of parameters, including different reaction temperature and time, methanol to oil molar ratio, the catalyst amount and the heating mode, have been examined in order to optimise the reaction conditions. For K-sepiolite, conversion of TGs to FAMEs close to $100 \%$ with almost $100 \%$ selectivity has been achieved in a batch type microwave reactor at $160{ }^{\circ} \mathrm{C}$. Unlike zeolite KA and ETS-10, potassium containing sepiolites lack long-term stability in the transesterification reactions due to its structural instability and loss of the active component during the recycling stages. Indeed, sepiolite structure undergoes irreversible changes upon heating above $250{ }^{\circ} \mathrm{C}$ resulting in dehydration of sepiolite and folding of its structure with the loss of the micropore channels. Impregnation with K-containing compounds also leads to partial structural degradation and decrease in the surface area. Subsequent thermal treatment, required for the decomposition of the metal precursor with the formation of an oxide on the support, can cause further detrimental structural changes. In contrast, both zeolite KA and ETS-10 show no structural degradation over several reaction and regeneration cycles displaying consistently high activity and selectivity in transesterification reactions and demonstrate a good deal of potential as basic microporous catalysts for biofuel production.

Acknowledgements This work was supported by Ministry of Oil/ Oil Marketing Company (SOMO), Baghdad, Iraq under Grant SL144-01A. The authors appreciate the support of the Lennard-Jones Laboratories at Keele University, UK, where this study was carried out.

Open Access This article is distributed under the terms of the Creative Commons Attribution 4.0 International License (http://creativeco mmons.org/licenses/by/4.0/), which permits unrestricted use, distribution, and reproduction in any medium, provided you give appropriate credit to the original author(s) and the source, provide a link to the Creative Commons license, and indicate if changes were made.

\section{References}

1. M.R. Avhad, J.M. Marchetti, Renew. Sustain. Energy Rev. 50, 696 (2015)

2. D. Srinivas, J.K. Satyarthi, Indian J. Chem. 51 A, 174 (2012)

3. N. Brun, P. Hesemann, D. Esposito, Chem. Sci. 8, 4724 (2017)

4. Standard specification for biodiesel fuel blend stock (B100) for middle distillate fuels. Report no. D6751-08.ASTM, 2008

5. L.C. Meher, D.V. Sagar, S.N. Naik, Renew. Sustain. Energy Rev. 10, 248 (2006)

6. BP Statistical Review of World Energy, June 2017. http://www. bp.com/content/dam/bp/pdf/energy-economics/statistical-revie w-2017/bp-statistical-review-of-world-energy-2017-full-repor t.pdf

7. M. Stöcker, Angew. Chem. Int. Ed. 47, 9200 (2008)

8. G.W. Huber, S. Iborra, A. Corma, Chem. Rev. 106, 4044 (2006)
9. C.D.B. Gutierrez, D.L.R. Serna, C.A.C. Alzate, Biofuel Res. J. 15, 691 (2017)

10. A.L. de Lima, C.M. Ronconi, C.J. Mota, Catal. Sci. Technol. 6, 2877 (2016)

11. K. Na, G.A. Somorjai, Catal. Lett. 145, 193 (2015)

12. A. Corma, R.M. Martin-Aranda, J. Catal. 130, 130 (1991)

13. A. Tangy, I.N. Pulidindi, A. Gedanken, Energy Fuels 30, 3151 (2016)

14. H.J. Alves, A.M. da Rocha, M.R. Monteiro, C. Moretti, M.D. Cabrelon, C.A. Schwengber, M.C. Milinsk, Appl. Clay Sci. 91, 98 (2014)

15. E. Sabah, M.S. Çelik, J. Am. Oil Chem. Soc. 82, 911 (2005)

16. F.E. Soetaredjo, A. Ayucitra, S. Ismadji, A.L. Maukar, Appl. Clay Sci. 53, 341 (2011)

17. E. Agustian, M. Ghozali, R. Savitri, S. Wuryaningsih, in Proceeding of International Conference on Sustainable Energy Engineering and Application, 2012, p. 35

18. N. Degirmenbasi, N. Boz, D.M. Kalyon, Appl. Catal. B 150, 147 (2014)

19. H.K. Nguyen, N.T. Dinh, N.L. Nguyen, D.T. Ngoc, J. Porous Mater. 24, 559 (2017)

20. H. Hisato, O. Ryohei, I. Naoya, Am Mineral. 53, 1613 (1969)

21. A. Philippou, J. Rocha, M.W. Anderson, Catal. Let. 57, 151 (1999)

22. D.E. Lopez, J.G. Goodwin, D.A. Bruce, E. Lotero, Appl. Catal. A 295, 97 (2005)

23. G.J. Suppes, M.A. Dasari, E.J. Doskocil, P.J. Mankidy, M.J. Goff, Appl. Catal. A 257, 213 (2004)

24. A. Preisingei, Clays Clay Miner. 6, 61 (1959)

25. J.E. Post, D.L. Bish, P.J. Heaney, Am. Mineral. 92, 91 (2007)

26. M.V. Kok, E. Sources, A. Part, Recover. Util. Environ. Eff. 35, 173 (2013)

27. M. Yeniyol, Clay Miner. 49, 91 (2014)

28. M. Suárez, J. García-Rivas, E. García-Romero, N. Jara, Appl. Clay Sci. 131, 124 (2016)

29. M.S. Yılmaz, Y. Kalpaklı, S. Pişkin, J. Therm. Anal. Calorim. 114, 1191 (2013)

30. A. Gómez-Avilés, P. Aranda, F.M. Fernandes, C. Belver, E. RuizHitzky, J. Nanosci. Nanotechnol. 13, 2897 (2013)

31. M. Pozo, J.P. Calvo, E. Pozo, Á Moreno, Appl. Clay Sci. 91-92, 30 (2014)

32. L.P. Ogorodova, I.A. Kiseleva, M.F. Vigasina, Y.K. Kabalov, R.O. Grishchenko, L.V. Mel'chakova, Am. Miner. 99, 2369 (2014)

33. R. Szostak, Handbook of Molecular Sieves: Structures (Springer, New York, 1992)

34. T.K. Das, A. Chandwadkar, S. Sivasanker, Chem. Commun. 10, 1105 (1996)

35. R.L. Frost, O.B. Locos, H. Ruan, J.T. Kloprogge, Vib. Spectrosc. 27, 1 (2001)

36. M. Mora, M.I. López, M. Carmona, C. Jiménez-Sanchidrián, J.R. Ruiz, Polyhedron 29, 3046 (2010)

37. P. Giustetto, K. Seenivasan, S. Bordiga, Periodico di Mineralogia 21 (2010)

38. V.J. Bukas, M.T. Sampodimou, V. Gionis, G.D. Chryssikos, Vib. Spectrosc. 68, 51 (2013)

39. M. Tsampodimou, V. Bukas, E.T. Stathopoulou, V. Gionis, G.D. Chryssikos, Am. Mineral. 100, 195 (2015)

40. H. Knözinger, S. Huber, J. Chem. Soc., Faraday Trans. 94, 2047 (1998)

41. G.E.G. Muciño, R. Romero, I. Garcia-Orozco, A.R. Serrano, R.B. Jiménez, R. Natividad, Catal. Today 271, 220 (2016)

42. N. Boz, N. Degirmenbasi, D.M. Kalyon, Appl. Catal. B 138-139, 236 (2013)

43. G. Sun, Y. Li, Z. Cai, Y. Teng, M.J.T. Reaney, Appl. Catal. B 209, 118 (2017)

44. O. Ilgen, A.N. Akin, Appl. Catal. B 126, 342 (2012) 
45. M. Villamiel, N. Corzo, M.I. Foda, F. Montes, A. Olano, Food Chem. 76, 7 (2002)

46. M. Opanasenko, Catal. Today. 243, 2 (2015)

47. O. Kikhtyanin, Y. Ganjkhanlou, D. Kubicka, R. Bulanek, J. Cejka, Appl. Catal. A 549, 8 (2018)
48. G. Busca, Microporous Mesoporous Mater. 254, 3 (2017)

49. A. Al-Ani, R. Darton, S. Sneddon, V. Zholobenko, ACS Appl. Nano Mater. 1, 310 (2018) 